\title{
Interval Type-2 Fuzzy Maximum Power Point Tracking Control for Wind Power Buck Coversion Systems
}

\author{
Ching-Chih Tsai * Chun-Chien Chang ** Chien-Cheng Yu*** Feng-Chun Tai \\ Department of Electrical Engineering, National Chung Hsing University \\ No.250, Kuo-Kuang Road, Taichung, Taiwan, ROC. \\ * e-mail: cctsai@nchu.edu.tw **email: daniel.chang@innolux.com, ${ }^{* * *}$ email: jenkenyu@gmail.com
}

\begin{abstract}
This paper develops a PI-like interval type-2 (IT2) fuzzy maximum power point tracking (MPPT) control method for a class of wind power generation and battery charging systems with DC/DC buck converters. After the brief model descriptions of the wind power turbine, generator and DC/DC buck converter, the proposed MPPT controller is designed using IT2 fuzzy control logics and its asymptotical stability is discussed. The effectiveness and merit of the proposed MPPT controller are exemplified by conducting several simulations via Matlab/Simulink and three experiments. The proposed controller is shown superior by comparing to a conventional PI MPPT controller and a PI-like type-1 fuzzy MPPT controller.
\end{abstract}

Keywords : Buck converter, fuzzy control, IT2 fuzzy control, maximum power point tracking (MPPT), PI control, wind power generation.

\section{INTRODUCTION}

In the trend of global carbon reduction and global climate warming, renewable energy development and greenhouse gas reduction have been becoming two important subjects of global electricity supply. Nowadays ocean-current power, solar power and wind power have been considered the most potential for such energy development. Ocean-current power has not been effectively utilized due to immature and uneconomic ocean-current power generation technology. In consideration of the natural environmental constraints as well as technical development and maturity conditions, solar photovoltaic power generation and wind power generation have been the most developed renewable or green energy options. In wind power generation, Taipower Company in Taiwan [1] has paid significant efforts to install many wind power generation stations; 283 wind turbines and power generation units was built till the end of the 2012, giving total installed capacities up to $559,660 \mathrm{~kW}$ and yearly generating capacities up to 1489.51 million kWH [1].

A wind power generation system is usually composed of one wind turbine, gearboxes, one power electric generator, one power converter and other important modules. The wind turbine is mainly powered by the moving air so as to turn wind blades to capture the wind's kinetic energy, and then convert it into useful mechanical or electrical energy.
The leaf-like blade rotor is driven to continuously spin by wind due to aerodynamic force, including lift force and resisting forces, thus generating rotational torque on the blades. Currently, the wind turbines can generally be divided into two types: horizontal and vertical. Basically, horizontal-axis turbines are shown to have higher power conversion efficiency than vertical -axis turbines do.

Since the performance of wind turbines are significantly affected by wind speeds, it is important to maintain the maximum power output of the wind power system at any time and any wind speed. In addition, the output power of the wind power generation system is also affected by electric loads connected to wind generators, and other factors including component aging, thereby causing the system to be unable to work on maximum power transfer. To output maximum power of the wind power generation system at any wind speed and any electric load, it is crucial to achieve maximum power point tracking for wind power generation systems

The maximum power point tracking methods for wind power generation have been investigated by many researchers. These methods van be classified into four categories: (i) disturbance observation method; (ii) frequency disturbance observation method; (iii) best approximation estimation method; (iv) fuzzy control method. Chiu et al. [3] proposed the TS fuzzy maximum power point tracking method [3] using DC-DC boost conversion, and applied the fast terminal sliding mode control strategy [4] to accomplish for DC-DC buck conversion. On the other hand, the interval type-2 fuzzy control method has been widely studied in [5-11], and has been shown effective for solar photovoltaic systems in [12]. However, this IT2 fuzzy control method has not been adopted in the field of wind power generation for all range of wind speeds.

The objectives of this paper are to develop a new type of interval type-2 (IT2) fuzzy maximum power point tracking (MPPT) for a stand-alone wind power and battery charging system, and to simulate the proposed controller via the use of the commercial software MATLAB / Simulink simulation. The presented contents are written in two technical contributions: one is the development of a stable PI-like IT2 fuzzy MPPT controller for all ranges of wind speeds, and the other is the comparative studies of the proposed controller and two existing MPPT controllers,conventional PI controller and type-1 


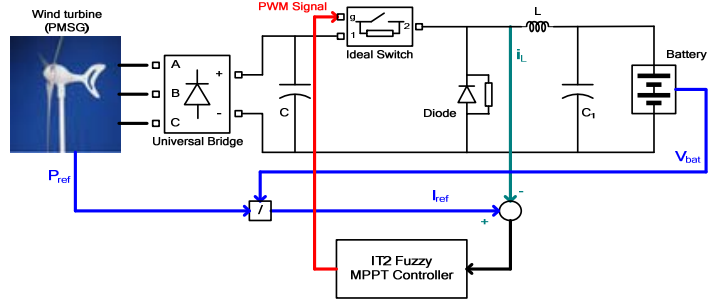

(a)

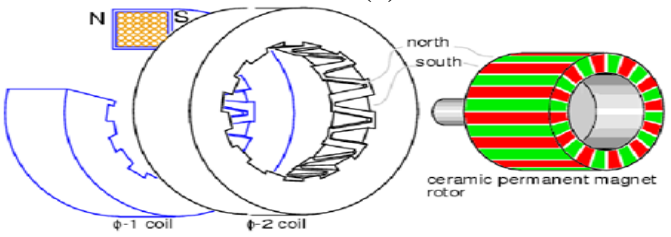

(b)

Fig. 1. (a)Diagram of a wind power buck-conversion and charging system;(b) Permanent magnet synchronous generator (PMSG)

fuzzy MPPT controller.

The rest of the paper is organized as follows. Section 2 briefly introduces the mathematical models of the wind turbine and the DC-DC buck converter. Section 3 proposes the PI-like IT2 type2 fuzzy logic controller, describes how to establish the IT2 fuzzy MPPT controller and discusses its asymptotical stability. Comparative studies are conducted in Section 4 , and experimental results are performed to show the applicability of the proposed controller. Section 6 concludes this paper.

\section{WIND POWER GENERATION MODEL}

This section is dedicated to describe mathematical models of the wind power charging system in the following two-step procedure. First, the wind power generation system is introduced in Fig.1; second, the averaging mathematical model of a DC-DC buck converter is briefly recalled.

\subsection{Wind Power Generation System}

Wind power is the conversion of wind energy into mechanical energy via a wind turbine, and then the rotational mechanical energy is converted to electrical energy via a wind power generator, which is the permanent magnet synchronous generator (PMSG). For the description of the dynamics of the PMSG, the reader is referred to [3]. Theoretically, the conversion efficiency of a wind power generation system can be up to $59.3 \%$. Since the horizontal-axis turbines are shown to have high power conversion efficiency which is up to $20-40 \%$, this type of turbine will be used in the paper in order to efficiently convert the kinetic energy of the wind into rotational mechanical energy of the turbine, and then drive the power generator to generate three-phase AC power. Since the wind power of the turbine is closely related to the air density, the radius of the blade and the wind speed, the relation regarding them is described in the following equation:

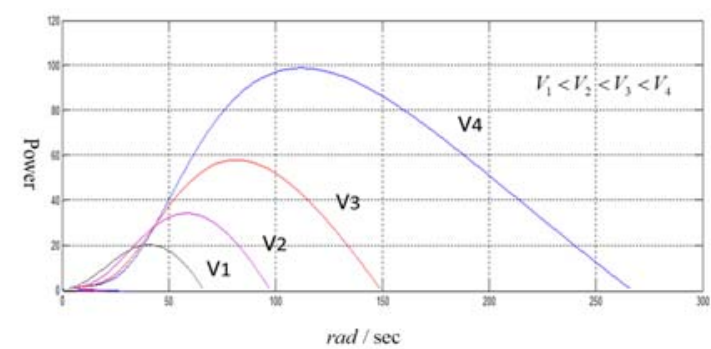

Fig. 2. Generated power at different wind speeds with respect to the generator speeds.

$$
p_{w}=\cdot \rho \cdot \pi \cdot S \cdot V_{w}^{3} / 2
$$

where $\rho$ is air density $\left(\mathrm{kg} / \mathrm{m}^{3}\right), S$ denotes the area of the rotor blades $\left(\mathrm{m}^{2}\right)$, and $V_{w}$ represents the wind speed ( $\mathrm{m} / \mathrm{sec}$ ). The output power of the wind turbine is almost equal to the electric power generated by the wind power generator, and the relation is given by

$$
P_{e}=C_{p}(\lambda, \beta) \cdot P_{w}
$$

where $C_{p}$ is the coefficient of the wind turbine performance, and it is defined as the ratio of the wind turbine output power and the turbine input power. Generally, the coefficient $C_{p}$ is

$$
C_{p}(\lambda, \beta)=C_{1}\left(C_{2} / \lambda_{i}-C_{3} \beta-C_{4}\right) e^{-C_{5} / \lambda i}+C_{6} \lambda
$$

and

$$
\frac{1}{\lambda_{i}}=\frac{1}{\lambda+0.08 \beta}-\frac{0.035}{\beta^{3}+1}
$$

where $\beta$ is the pitch angle of the wind turbine blades ; $\lambda$ is called the tip speed ratio between the wind turbine blade tip speed and the wind speed, and $\lambda$ is governed by the following formula:

$$
\lambda=\left(R \cdot \omega_{m}\right) / V_{w}
$$

where $\omega_{m}(\mathrm{rad} / \mathrm{s})$ is the speed of the mechanical rotor; is the radius of the rotor blades ( $\mathrm{m}$ ). Therefore, combining equations (1) and (5) yields the shaft torque of the wind turbine

$$
T_{w}=\frac{p_{w}}{\omega_{m}}=\frac{\rho \cdot S \cdot R \cdot V_{w}{ }^{2} \cdot C_{p}}{2 \lambda}
$$

Notice that equation (3) shows that the relation between both parameters, $C_{p}$ and $\lambda$, is nonlinear. nonlinear. When the electric load connected tothe wind turbine is small, the wind turbine will run at a high speed; when the load slowly increases, the wind turbine will slow down its speed. Thus, in a fixed wind speed, the electric load affects output voltage and efficiency of the wind generator significantly.

To attain maximum power output, power engineers should operate the wind power generation system in the optimal condition, namely that the optimum tip speed ratio $\lambda=\lambda_{\text {opt }}$ and the maximum value $C_{p}=C_{p \max }$ are satisfied. The maximum generated power can be is found at a wide range of generator speeds, as shown in Fig. 2. Assume that $\lambda_{\text {opt }}$ and $C_{p \max }$ are known, the maximum electric 


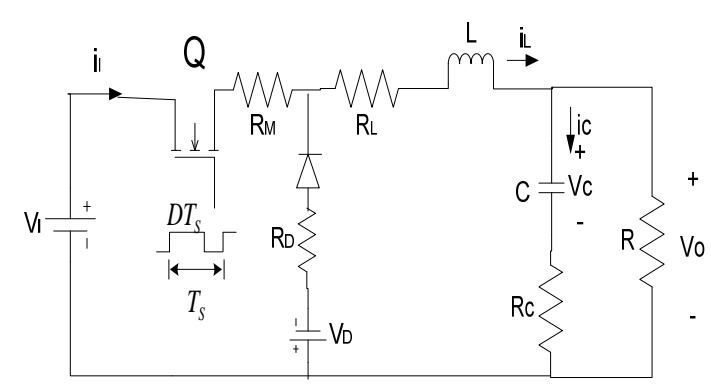

Fig. 3. Circuitry of the DC-DC buck converter.

power from the wind power generator is

$P_{r e f}=P_{q x}=C_{p \max }\left(\lambda_{q p}, \beta\right) \cdot P_{w}=\frac{1}{2} \cdot C_{p \max }\left(\lambda_{q p}, \beta\right) \rho \cdot \pi \cdot S \cdot V_{w}^{3}=K_{q p} V_{w}^{3}$

where $K_{o p t}=C_{p \max }\left(\lambda_{o p t}, \beta\right) \rho \pi S / 2$. Worthy of mention is that $P_{\text {ref }}$ is used to design a fuzzy MPPT control law such that the generated maximum electric power $P_{\text {ref }}$ from the turbine side can be transferred to the electric load side.

\subsection{DC-DC Buck Converter}

Since the wind power generator with the wind turbine provides three-phase high-voltage AC power, The DC power is then rectified by a three-phase full-wave rectifier, and then rectified DC power is further processed to obtain low-voltage for batter charging by a DC-DC buck converter. As shown in Fig. 3, this type of converter is equipped with one power transistor, one power diode, two capacitors and one inductor. The converter accepts the high-voltage $\operatorname{input} V_{I}$, and then provides appropriate low-voltage output $V_{0}$ for the battery charging system. The power transistor is continuously switched on and off by its PWM signals, in order to carry out its buck function. Let $t_{o n}$ and $t_{\text {off }}$ respective denote the switch-on and switch-off time at a fixed switching period $T_{S}$. Under two assumptions: the inductor current is continuous, and there are no voltage drops in the

$$
V_{O} / V_{I}=D=t_{O N} / T_{S}, D \in[0,1]
$$

On the other hand, the averaging dynamics of the DC-DC buck converter can be derived via the so-called averaging method in the steady-state operation mode. With help of the Kirchhoff laws regarding node current and loop voltage, the averaging state and output equation of the buck converter is expressed as follows;

$$
\begin{aligned}
{\left[\begin{array}{c}
\dot{i_{L}} \\
\dot{V}_{C}
\end{array}\right]=} & {\left[\begin{array}{cc}
-\frac{1}{L}\left(R_{D}+R_{L}+\frac{R_{C} R}{R_{C}+R}\right) & \frac{-R}{L\left(R_{C}+R\right)} \\
C \frac{R}{\left(R_{C}+R\right)} & \frac{-1}{C\left(R_{C}+R\right)}
\end{array}\right]\left[\begin{array}{c}
i_{L} \\
V_{C}
\end{array}\right] } \\
& +\left[\begin{array}{c}
\frac{1}{L}\left[\left(R_{D}+R_{m l}\right) i_{L}+V_{D}+V_{I}\right] \\
0
\end{array}\right] D+\left[\begin{array}{c}
-\frac{V_{D}}{L} \\
0
\end{array}\right](9)
\end{aligned}
$$

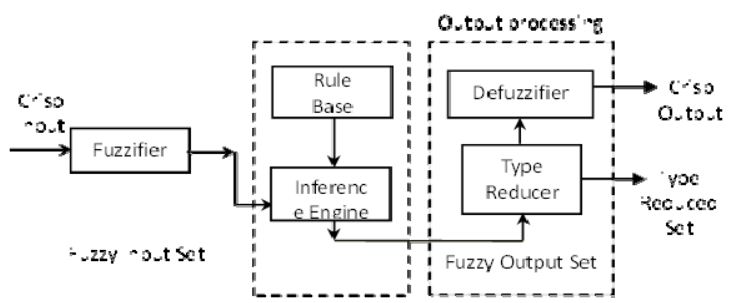

Fig.4. Interval type-2 fuzzy logic system.

\begin{tabular}{|c|c|c|c|c|c|c|}
\hline NB & NM & NS & PS & PM & PB & \\
\hline z & NS & NM & NM & NB & NB & PB \\
\hline PS & z & NS & NM & NM & NB & PM \\
\hline PM & PS & $z$ & NS & NM & NM & PS $\boldsymbol{c}^{t}$ \\
\hline PM & PM & PS & $z$ & NS & NM & NS ${ }^{\circ}$ \\
\hline PB & PM & PM & PS & $z$ & NS & NM \\
\hline PB & PB & PM & PM & PS & z & NB \\
\hline
\end{tabular}

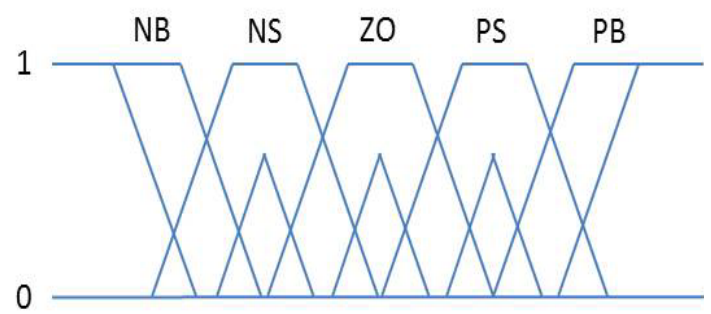

Fig. 5. IT2 Triangular membership functions.

Fig.6. Fuzzy rules of the proposed fuzzy controller.

$$
V_{O}=\left[\begin{array}{ll}
\frac{R_{C} R}{R_{C}+R} & \frac{R}{R_{C}+R}
\end{array}\right]\left[\begin{array}{c}
i_{L} \\
V_{C}
\end{array}\right]
$$

power transistor and diode, the steady-state relationship between the input voltage $V_{I}$ and the output voltage $V_{0}$ is dominated by the duty ratio, $D=t_{O N} / T_{S}$, and expressed by the following equation. where $V_{o}$ is the output voltage ; $i_{L}$ and $V_{c}$ are respectively the inductor current and the capacitor voltage; $D$ is the duty ratio; $L, C$ and $R_{L}$ mean the inductance, capacitance and load resistance of the converter; $R_{C}, R_{D}$ and $R_{m l}$ are the resistance values of the capacitor, diode and inductor, respectively. $V_{D}$ is the diode forward voltage.

\section{IT2 FUZZY MPPT CONTROL}

\subsection{Interval type-2 Fuzzy Logic System}

As shown in Fig. 4, the interval type-2 fuzzy logic system (IT2FLS) usually includes five modules: fuzzifier, fuzzy rules, fuzzy inference, type reduction and defuzzifier. Typical membership functions of the IT2FLSs are Gaussian, triangular and trapezoidal. Fig.7 shows the used triangular membership functions 


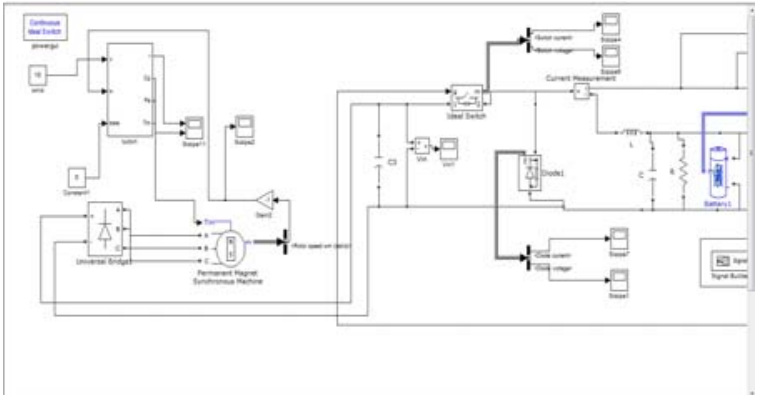

(a)

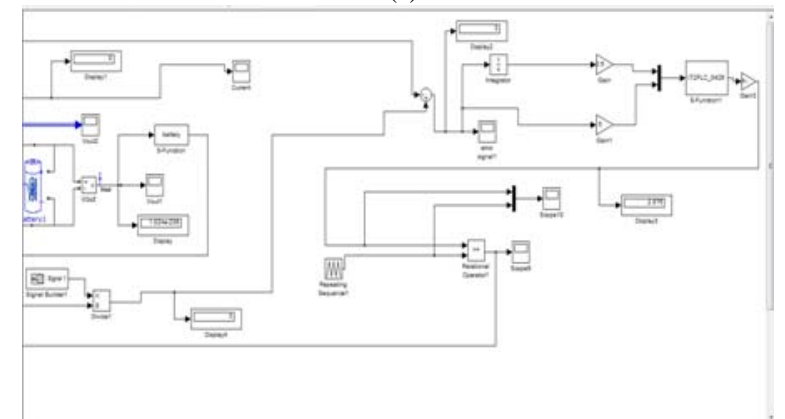

(b)

Fig.7. Simulink model of the proposed PI-like interval type-2 fuzzy MPPT controller of the wind power charging system: (a) wind power generator and DC-DC buck converter;(b) PI-like IT2 Fuzzy MPPT controller.

of the IT2FLS containing five linguistic variables: PB (positive big), PS (positive small), ZO (zero), NS (negative small), and NB (negative big). As shown in Fig.5, the IT2FLS membership functions have lower and upper bounds, $\left(\bar{\mu}_{\tilde{A}}(x)\right)$ and $\left(\underline{\mu}_{\tilde{A}}(x)\right)$. Fuzzy rules of the IT2FLS is almost similar to those for the conventional type-1 FLS, which takes IF-THEN rules, each of which maps from the input space to the output space. Fig. 6 depicts the fuzzy rules of the PI-like IT2 fuzzy controller.

The fuzzy inference engine is a decision-making logic, which employs fuzzy rules from the fuzzy rule base to determine the mapping from the fuzzy input set to the fuzzy output set. In our IT2FLS, the product operation is considered. Type reduction is aimed to compute the firing rules and the corresponding rule consequents. Among several methods, the most commonly used center-of-set type reduction algorithm, called Karnik-Mendel (KM) algorithm), is used to efficiently get the right and left limits, $y_{R}$ and $y_{L}$. The function of the defuzzifier is to get a crisp output by taking the average value of $y_{R}$ and $y_{L}$ by $y=\left(y_{R}+y_{L}\right) / 2$.

\subsection{PI-Like IT2 Fuzzy Logic Control}

This subsection will delineate how to develop the PI-like IT2 fuzzy logic controller (IT2FLC). This IT2FLC has the two input variables, the error signal $x_{1}=e$ and the integral of the error signal, $x_{2}=\int_{0}^{t} e(\tau) d \tau$. In particular, the triangular fuzzy membership functions shown in Fig. 5 are displayed for seven selected linguistic variables of PB, PM, PS, ZO, NS,
NM, NB. Below are the 49 fuzzy rules.

$$
\begin{aligned}
& R_{1}: I F x_{1} \text { is } \tilde{F}_{1}^{1} \text { and } x_{2} \text { is } \tilde{F}_{2}^{1} \text { then } y_{1} \text { is }\left[\begin{array}{ll}
w_{l}^{1} & w_{r}^{1}
\end{array}\right] \\
& R_{2}: I F x_{1} \text { is } \tilde{F}_{1}^{2} \text { and } x_{2} \text { is } \tilde{F}_{2}^{2} \text { then } y_{1} \text { is }\left[\begin{array}{ll}
w_{l}^{2} & w_{r}^{2}
\end{array}\right] \\
& R_{3}: I F x_{1} \text { is } \tilde{F}_{1}^{3} \text { and } x_{2} \text { is } \tilde{F}_{2}^{3} \text { then } y_{1} \text { is }\left[\begin{array}{ll}
w_{l}^{3} & w_{r}^{3}
\end{array}\right] \\
& R_{49}: I F x_{1} \text { is } \tilde{F}_{1}^{49} \text { and } x_{2} \text { is } \tilde{F}_{2}^{49} \text { then } y_{1} \text { is }\left[\begin{array}{lll}
w_{l}^{49} & w_{r}^{49}
\end{array}\right]
\end{aligned}
$$

Fig. 6 depicts the 49 fuzzy rules and the linguistic variable, $y_{1}$ as the system output. The proposed PI-like IT2FLC adopts the interval triangular membership functions, product inference engine, the KM type-reduction algorithm type reduction, and the average method to obtain the final crisp output.

\subsection{PI-like IT2 Fuzzy MPPT Control}

This section will combine the aforementioned PI-like IT2FLC and maximum power point tracking (MMPT) theory for developing an IT2 fuzzy MPPT controller, in order to achieve the maximum power point tracking control for the wind power generation and battery charging system. Since the output power of the wind power generator usually depends upon different wind speeds and load changes, the proposed PI-like IT2 fuzzy MPPT controller maximizes the output power of the wind power system by appropriate adjustment of the duty cycle of the DC-DC buck converter to accomplish impedance matching.

In what follows, particular attention is paid to describe the proposed controller for the wind power charging system, as shown in Fig. 7. In Fig. 7, the permanent magnetic wind generator is powered by the wind turbine, thereby generating speed-dependent three-phase AC power. The AC power is then rectified into corresponding DC power via a three-phase full-wave rectifier. The DC-DC buck converter not only converts the high-voltage DC power into low-voltage DC power for charging batteries, but also achieves the maximum power point tracking control for the output of the wind power system. Different from conventional MPPT control strategies, the proposed MPPT control policy is aimed to let the inductor current track reference current commands via the DC-DC buck converter. The main idea behind this is that given the maximum output power, $P_{r e f}$ in (7), of the wind generator at some wind speed, the desired current command, $I_{r e f}$, is obtained from the relation $I_{\text {ref }}=P_{\text {ref }} / V_{b a t}$, where $V_{b a t}$ represents the battery voltage. Once the desired current command, $I_{\text {ref }}$, is calculated at any time, the proposed PI-like IT2 fuzzy MPPT controller is applied to track the desired current by finding the error current $e=I_{\text {ref }}-I$ and integral of the error current $e$, calculating the closed-loop fuzzy MPPT control law, and generating a fuzzy-adjusted output duty cycle D. The buck 
converter is controlled to adjust the output current until the current error converges to zero, thus carrying out the maximum power point tracking control. Worthy of mention is that the proposed IT2 fuzzy MPPT controller achieve MPPT not only for a specified wind speed, but also for a wind range of wind speeds, namely that the proposed controller is effective for all the range of speeds.

\subsection{Stability Analysis}

This subsection will discuss the asymptotical stability of the proposed IT2 fuzzy MPPT controller. In doing so, let us consider equation (9) by setting the capacitor voltage $V_{C}$ equal to the battery voltage $V_{b a t}$. Therefore, the dynamic equation of the current passing through the inductor can be regarded as a first-order system model with the control D and a constant exogenous input or disturbance. When the conventional PI controller is applied to achieve the closed-loop current feedback control, the closed-loop asymptotical stability and constant disturbance rejection of the overall closed-loop system can be easily accomplished because the PI controller is of type 1 , and both proportional and integral gains can be appropriately designed. Moreover, it has been known that the PI-like IT2 fuzzy PI controller can be thought of as a PI controller with time-varying gains. Since the proposed controller is still of type 1 , its closed-loop stability and disturbance rejection ability can be achieved by appropriately adjusting the controller parameters, such as the input scaling gains,membership functions, output scaling gains and so on. Furthermore, the proposed controller is able to obtain no tracking error for any constant wind speed and any constant disturbances.

\section{SIMULATIONS AND DISCUSSION}

This section is devoted to examining the effectiveness and merit of the proposed PI-like IT2 fuzzy MPPT controller for the wind power charging system. In addition, performance comparisons are made between the proposed controller and a conventional PI controller, and a conventional type-1 fuzzy MPPT controller. All the numerical simulations are done by the commercial software: Matlab/ Simulink. All the simulations use the following parameters: for the DC-DC buck converter, $L=30 \mathrm{mH}, C=1 \mathrm{mF}, \quad R_{L}=3200 \Omega$, the PWM frequency of the converter is $1000 \mathrm{~Hz}$, and the rated voltage of the charging batteries is DC $12 \mathrm{~V}$; the conventional PI controller is with $K_{P}=10, K_{I}=10 / 1000=0.01$; the used small wind power generator is $\mathrm{Z}-100 \mathrm{~W}$ whose weight is $2.8 \mathrm{~kg}$, rated wind speed is $12 \mathrm{~m} / \mathrm{sec}$, rated speed is 750rpm, and the maximum output power is $100 \mathrm{~W}$. Furthermore, the wind generator is a kind of permanent magnet three-phase AC power generator giving the rated output voltage $24 \mathrm{~V}$, and the best parameter $K_{\text {opt }}=0.1389$.

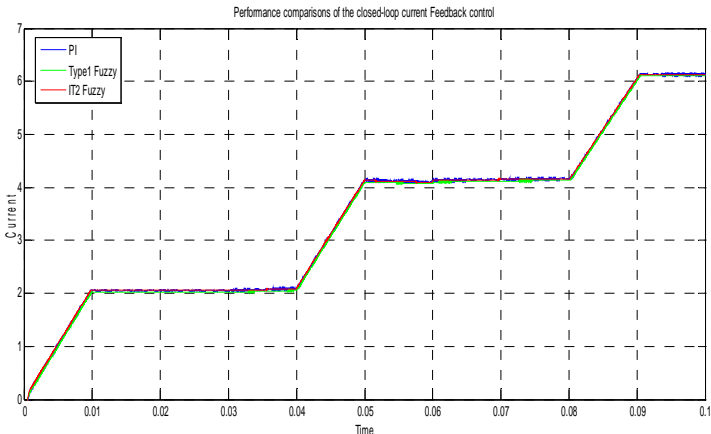

Fig. 8. Performance comparisons of the closed-loop current feedback control using PI controller, PI-like fuzzy MPPT controller and PI-like interval type-2 fuzzy MPPT controller under different reference power $P_{r e f}=30 \mathrm{~W}, 60 \mathrm{~W}, 90 \mathrm{~W}$.

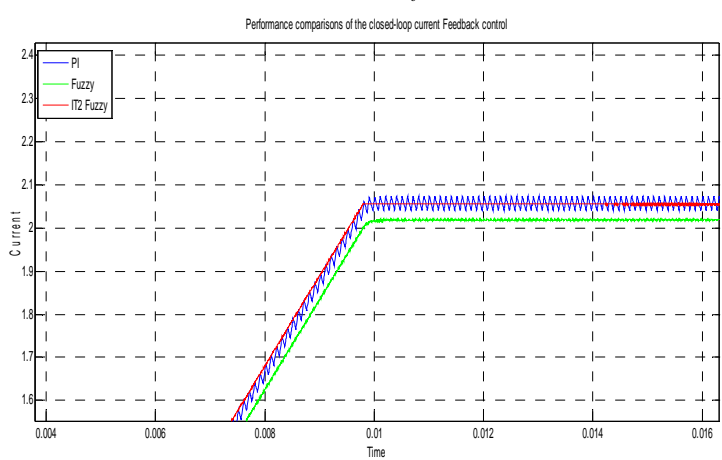

Fig. 9. Exploded portion of Performance comparisons of the closed-loop current feedback control using PI controller, PI-like fuzzy MPPT controller and PI-like interval type-2 fuzzy MPPT controller.

In the simulations, the wind speeds are respectively set by $6 \mathrm{~m} / \mathrm{sec}, 7.56 \mathrm{~m} / \mathrm{sec}$ and $8.65 \mathrm{~m} / \mathrm{sec}$, thus delivering the corresponding maximum output power values of the wind power generator as $P_{\text {ref }}=30 \mathrm{~W}, 60 \mathrm{~W}$, and $90 \mathrm{~W}$. Figs.8 and 9 compare the step-like current tracking results of the t PI controller, type-1 fuzzy MPPT controller and the IT2 fuzzy MPPT controller for the three cases; the results show that the proposed IT2 fuzzy MPPT is superior to the fixed-gain PI controller and the conventional type-1 fuzzy MPPT controller in terms of fast step tracking performance, smaller steady-state tracking errors and robustness over a wide variety of wind speed changes.

\section{EXPERIMENTAL RESULTS AND DISCUSSION}

In this section, two experiments are conducted to demonstrate the performance of the proposed IT2 fuzzy MPPT controller. The buck converter was constructed by using $L=300 \mu \mathrm{H} / 10 \mathrm{~A}$, $C=1000 \mu \mathrm{F} / 50 \mathrm{~V}$, the MOSFET RF540 from Vishay, one Diode MBR2060 from Motorola, and the PWM frequency of the converter was $20 \mathrm{kHz}$, and the rated voltage of the charging batteries is DC $12 \mathrm{~V}$. The two experiments were performed by the two wind generator speeds which were respectively set by 400 $\mathrm{rpm} / \mathrm{min}$ (wind speed is $9 \mathrm{~m} / \mathrm{s}$ ) and 700 $\mathrm{rpm} / \mathrm{min}$ (wind speed is $11.5 \mathrm{~m} / \mathrm{s}$ ), in order to deliver the corresponding maximum output power values of 


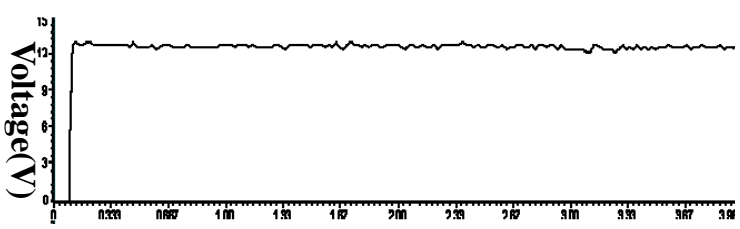

Time/Sec

Fig. 10. The battery voltage.

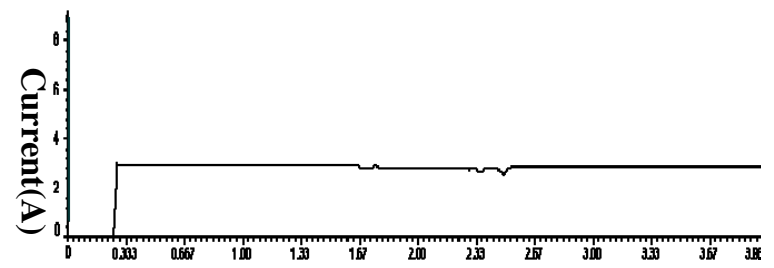

Time/Sec

Fig. 11. Experimental results of the closed loop current feedback control using proposed MPPT controller at the reference power $P_{\text {ref }}=40 \mathrm{~W}$ with corresponding current of $3 \mathrm{~A}$.

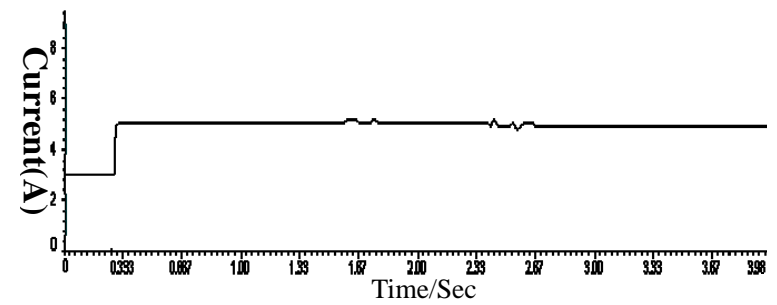

Fig. 12. Experimental results of the closed loop current feedback control using proposed MPPT controller under two reference power commands, $P_{\text {ref }}=40 \mathrm{~W}$ and $70 \mathrm{~W}$ with respective currents of $3 \mathrm{~A}$ and $5 \mathrm{~A}$.

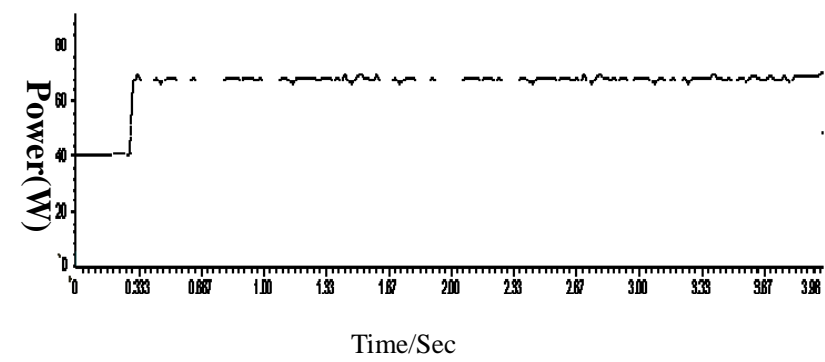

Fig. 13. Experimental results of the output power of the wind power buck conversion system

the wind power generator as $=40 \mathrm{~W}$ and $70 \mathrm{~W}$. Fig. 10 shows the measured battery voltage during the experimentation process, and Fig. 11 depicts the results of the closed-loop current feedback control using proposed MPPT controller in which the output current was 3A. Fig. 12 displays the results of the closed-loop current control using the proposed MPPT controller; for both cases of $=40 \mathrm{~W}$ and $70 \mathrm{~W}$, the output currents were $3 \mathrm{~A}$ and $5 \mathrm{~A}$, respectively. Fig. 13 illustrates the output power of the controlled wind power conversion with battery charging system. The results in Figs. 12-13 reveal that the proposed PI-like interval type-2 (IT2) fuzzy MPPT controller works well as predicted.

\section{CONCLUSIONS AND FUTURE WORK}

This paper has presented a PI-like interval type-2 (IT2) fuzzy MPPT controller for a wind power generation and battery charging system turbine system under a wide range of wind speeds. The proposed PI-like interval type-2 fuzzy MPPT controller has been developed by combining the conventional PI control and the IT2 fuzzy logic system, and its closed-loop asymptotically stability has been proven in some details. Through simulations via MATLAB / Simulink, the proposed IT2 fuzzy MPPT controller has been shown capable of not only giving satisfactory tracking performance for different wind speeds, but also providing superior robustness in the presence of measurement noise. Experimental results will be conducted soon in order to show the applicability of the proposed PI-like interval type-2 (IT2) fuzzy MPPT controller for wind power buck conversion system.

\section{ACKNOWLEDGEMENTS}

The authors gratefully acknowledge financial support from National Science Council, the Republic of China, under contract NSC 101-2218-E-046-MY2.

\section{REFERENCES}

[1] http://www.taipower.com.tw.

[2] C. S Shieh, Maximum power tracking control of Solar PV systems, Master Thesis, Department of Electrical Engineering, National Chung Hsing University, July 2010.

[3] C. S Chiu, Z.-H. Li, and Y.-H. Chen, "T-S Fuzzy Direct Maximum Power Point Tracking of Wind Energy Conversion Systems," International Journal of Fuzzy Systems, Vol. 15, No. 2, pp. 192-202,June 2013.

[4] C. S. Chiu, T. S. Chaing, M. L. Chou, W. J. Hung, J. H. Liu, "Maximum Power Point Tracking of Wind Power Systems via Fast terminal Sliding Mode Control, "accepted for presentation at 2014 International conference on Control and Automation, Taichung, Taiwan, June 2014.

[5] N.N. Karnik, J.M. Mendel and Q. Liang, "Type-2 Fuzzy Logic Systems," IEEE Transaction on Fuzzy Systems, vol. 7, pp. 643-658, 1999.

[6] Q. Liang and J.M. Mendel, "Interval Type-2 Fuzzy Logic Systems: Theory and Design," IEEE Transactions on Fuzzy Systems, vol. 8(5), pp. 535-550, 2000.

[7] T. Kumbasar, I. Eksin, M. Guzelkaya and E. Yesil, "Type-2 fuzzy model based controller design for neutralization processes," ISA Transactions, vol. 51 (2), pp. 277-287, 2012.

[8] D. Wu and W. W. Tan, "Genetic Learning and Performance Evaluation of Internal Type-2 Fuzzy Logic Controllers," Engineering Applications of Artificial Intelligence, vol. 19, pp. 829-841, 2006

[9] O. Castillo, G. Huesca and F. Valdez, "Evolutionary Computing for Optimizing Type-2 Fuzzy Systems in Intelligent Control of Non-Linear Dynamic Plants," In Proceeding of North American Fuzzy Information Processing Society, pp. 247-251, 2005.

[10] M. Aliasghary, I. Eksin, M. Guzelkaya and T. Kumbasar, "Design of an interval type-2 fuzzy logic controller based on conventional PI controller," In: Proc. Int. Conf. MED, pp. 627-632, 2012.

[11] D. Wu, "Twelve Considerations in Choosing between Gaussian and Trapezoidal Membership Functions in Interval Type-2 Fuzzy Logic Controllers," 2012 IEEE World Congress on Computational Intelligence, Brisbane, Australia, June 2012.

[12] C. Y. Li, Design and Implementation of Fuzzy Controller for Fuel Cell and Photovoltaic Generation Systems, Master Thesis, Department of Electrical Engineering, National Cheng Kung University, June 2012. 